\title{
Empatía y moralidad: las dimensiones psicológicas y filosóficas de una relación compleja
}

\author{
Belén Altuna ${ }^{1}$
}

Recibido: 28 de junio de 2016 / Aceptado: 1 de marzo de 2017

Resumen. Para algunos la empatía es "el centro del universo moral", mientras que para otros juega un papel secundario o, en todo caso, éticamente poco fiable. Acudiendo tanto a sus precursores filosóficos -como Hume y Smith-, como a sus investigadores contemporáneos en el campo de la psicología como Hoffman y Batson-, este artículo elabora una defensa ponderada del papel de la empatía en la motivación, el desarrollo y el juicio morales, reconociendo sus limitaciones.

Palabras clave: empatía; adopción de perspectiva; David Hume; Martin L. Hoffman; parcialidad/ imparcialidad; egoísmo/altruismo.

\section{[en] Empathy and morality: the psychological and philosophical dimensions of a complex relationship}

\begin{abstract}
For some empathy is "the center of the moral universe", while for others it plays a secondary role or, in any case, ethically unreliable. Attending to its philosophical precursors such as Hume and Smith, and its contemporary researchers in the field of psychology, as Hoffman and Batson, this article develops a balanced defense of the role of empathy in moral motivation, development and judgment, recognizing its limitations.
\end{abstract}

Keywords: empathy; perspective taking; David Hume; Martin L. Hoffman; partiality/impartiality; egoism/altruism.

Sumario: 1. Empatía: mecanismo psicológico e implicación moral; 1.1. De los precursores filosóficos a la investigación empírica contemporánea; 1.2. Un problema de definición: la empatía es afectiva, además de cognitiva; 1.3. Los mecanismos de la empatía: del contagio emocional a la adopción de perspectiva; 1.4. La hipótesis Empatía-Altruismo y otras implicaciones; 2. Sesgos y limitaciones de la empatía; 2.1. Parcialidad por inmediatez, familiaridad y semejanza; 2.2. Empatía y contra-empatía; 2.3. El interruptor que se enciende y se apaga; 3. Empatía e ideal regulativo: la combinación ética; 3.1. Empatía: "centro del universo moral" para algunos, elemento distorsionador para otros; 3.2. Casos de conflicto entre empatía (atención, cuidado) y justicia; parcialidad e imparcialidad; 3.3. En busca de una empatía regulada por un ideal normativo; 3.4. Empatía y moralidad, en resumen; 4. Referencias bibliográficas.

Cómo citar: Altuna, B. (2018): "Empatía y moralidad: las dimensiones psicológicas y filosóficas de una relación compleja”, en Revista de Filosofía 43 (2), 245-262.

1 Universidad de País Vasco, UPV/EHU

belen.altuna@ehu.eus 
Tantos siglos dando por sentada la idea hobessiana del hombre como lobo para el hombre; tantos siglos afirmando nuestra naturaleza pecaminosa, nuestra madera torcida, nuestra inclinación al mal, al vicio, a la violencia; tantos discursos filosóficos, religiosos y psicoanalíticos bendiciendo, implícita o explícitamente, la teoría del egoísmo universal, el retrato de las mezquinas criaturas que no saben moverse sino por su propio interés; tantas arengas morales exhortándonos a luchar contra nuestros instintos, nuestras inclinaciones y deseos; tanta insistencia en que superáramos nuestra naturaleza animal, en que dejáramos de lado ese amasijo de emociones y fuéramos unos perfectos calculadores racionales, y ahora... Ahora, algo ha cambiando (y no ha sido, evidentemente, la naturaleza humana).

Algo está sucediendo en las últimas décadas, algo que tiene que ver con que diversas ciencias - desde la biología evolutiva a la psicología experimental y social, desde las neurociencias a la primatología- estén tomándose muy en serio, como nunca antes, el estudio de la moralidad. Y con que los datos y los resultados que nos trasmiten distan mucho de proporcionar una imagen tan sombría y egoísta del animal humano. Evidentemente, no podemos explorar aquí las múltiples vertientes del estudio científico del fenómeno moral, pero sí podemos interrogarnos sobre la que es una de sus principales "joyas de la corona": la empatía.

\section{Empatía: mecanismo psicológico e implicación moral}

\subsection{De los precursores filosóficos a la investigación empírica contemporánea}

El término "empatía" apenas tiene cien años de existencia ${ }^{2}$, pero por supuesto no así el fenómeno al que hace referencia, solapado durante siglos por los que ahora se consideran algunos de sus posibles efectos: benevolencia, compasión, bondad, humanidad, interés y preocupación por el otro, etc.; $\mathrm{y}$, sobre todo, totalmente equiparable al concepto de simpatía, tal como fue desarrollado en la ilustración escocesa por David Hume (especialmente en el Tratado de la naturaleza humana, 1740) y Adam Smith (Teoría de los sentimientos morales, 1759).

Hume y Smith, siguiendo a Hutcheson, respondían entre otros a Bernard Mandeville, que en 1714 había reavivado la polémica hobbesiana con su Fabula de las abejas, al postular una vez más que detrás de todos nuestros actos, incluidos los de apariencia más benévola o generosa, no latía sino el interés propio, el egoísmo, y añadiendo además que tampoco habría de importarnos, puesto que sus consecuencias sociales eran en conjunto beneficiosas. Pues bien, Hume y Smith se esforzaron en mostrar que la naturaleza humana no era así, o al menos no era sólo así. Siguiendo la tradición empirista, ambos afirmaron que la moral es antes que nada sentida, una percepción de agrado o desagrado dependiendo del dolor o placer que nos produzca

2 El concepto empezó como Einfühlung en la estética alemana de finales del siglo XIX y fue traducido como empathy en la psicología experimental americana de principios del XX. Después, como resume Wispé (en Eisenberg/Strayer, 1992, p. 27), "fue utilizado por muchos teóricos de la personalidad en la década de los 30; fue retomado y revitalizado, especialmente por los psicoterapeutas rogerianos, durante los años 50; tuvo un breve encuentro con los teóricos del condicionamiento en los años 60; y, más recientemente, ha sido utilizado por psicólogos sociales y evolutivos para explicar la conducta altruista". Por cierto que el término altruismo, con el que a menudo suele relacionársele (y especialmente en la conocida teoría de Batson, 1991), tampoco es mucho más antiguo: fue acuñado por Auguste Comte en 1851. 
lo que estamos observando o considerando. Pero lo que ambos subrayaron es que esa percepción no se produce únicamente con aquello que nos afecta de manera directa, sino también con lo que afecta a otros, porque las mentes, sentenció Hume premonitoriamente, "son espejos unas de otras" (2005, p. 499), es decir, tenemos una capacidad natural para comunicar o transferir las emociones de uno a otro, de manera que constantemente nos sentimos afectados, tocados o contagiados por las emociones de otros a través de la simpatía. Todo ello nos convierte en animales en extremo sociables y comunicativos (y no sólo a través de la palabra) y muestra la moral como un asunto naturalmente intersubjetivo: en absoluto como un trato o contrato entre individuos aislados y (únicamente) autointeresados. La benevolencia y el sentimiento de humanidad nacerían de ese compartir natural que es la simpatía, según Hume y Smith, aunque desde luego no negarán que ésta tiene que lidiar con las pasiones egoístas e, incluso, con las limitaciones propias de la simpatía (de las que luego hablaremos).

Apesar de la influencia de estos pensadores, lo cierto es que en gran parte de la teoría filosófica, psicológica, sociológica o económica posterior (el homo economicus) ha prevalecido, de manera implícita o explícita, la teoría del egoísmo universal; como ha prevalecido igualmente el planteamiento racionalista y deontológico de la moral, tildando a su vez a los sentimientos de irracionales, debilitantes o peligrosos. En las últimas décadas, sin embargo, esto ha ido cambiando sensiblemente. Múltiples investigaciones y enfoques, teorías y libros, han ido rescatando o reivindicando ese otro legado, llegando incluso en la actualidad a cierto boom en torno a la empatía. No son pocos quienes afirman que es la clave de toda moralidad, quienes la describen como "el pegamento de las relaciones sociales" (Baron-Cohen, 2005, p. 38), "el cemento del universo moral" (Slote, 2010, p. 13), "la chispa del interés del hombre por los demás, el aglutinante que hace posible la vida social" (Hoffman, 2002, p. 12), quienes hablan de que vivimos en La era de la empatía (De Waal, 2011), o de que, en realidad, somos homo empathicus y de que nos dirigimos hacia una civilización empática (Rifkin, 2010).

El resultado es una cierta confusión en torno al término y, en muchos casos, una sobrevaloración de su influencia moral. Más de uno minimiza su tendencia a la parcialidad, olvidando que, en primer lugar, la empatía es una experiencia psicológica; no, sin más, un principio normativo ${ }^{3}$. Puede que sea el mecanismo fundamental de nuestra sociabilidad e intersubjetividad, pero eso no lo hace, sin más, moral, en el sentido de adecuado a las normas y los principios éticos. Es claro que parece fomentar un punto de vista sensible y personal (interpersonal), pero no siempre casar bien con el punto de vista impersonal e imparcial que demandan las reglas de justicia. El camino que va de la empatía a la ética parece más bien estar lleno de recovecos, y son las sinuosidades de esa ruta las que vamos a explorar a continuación.

Para el propósito de este artículo, dejaré a un lado los mecanismos neurológicos que podrían estar en su base (como las neuronas espejo), los estudios etológicos que muestran un origen evolutivo común, o las discusiones sobre teoría de la mente ${ }^{4}$,

Como subraya muy bien Oxley (2011, p. 6), ahondando en esa confusión habitual. A su juicio, las funciones más importantes de la empatía son epistémicas, no directamente morales.

4 Desde los años 90, hay dos teorías enfrentadas respecto a la cuestión de cómo podemos comprender la mente ajena: a) para la teoría de la mente o teoría-teoría, nuestra capacidad de predecir, explicar e interpretar a los otros agentes implica de manera esencial el conocimiento popular que tenemos de la psicología de los 
para centrarme en la discusión psicológica y filosófico moral en torno a la empatía. Nuestro objetivo es explorar cómo funciona ésta, cómo nos ponemos en la piel de los otros, y qué aporta ese conocimiento a la comprensión de la moralidad.

\subsection{Un problema de definición: la empatía es afectiva, además de cognitiva}

En parte, la confusión viene del hecho de que no haya una definición aceptada ${ }^{5}$ por todos, tal vez por la diversidad de disciplinas que analizan el fenómeno. Aún así, si acudimos a sus estudiosos más reputados en el campo de la psicología, encontramos definiciones que se aproximan bastante entre sí:

La empatía implica compartir la emoción percibida en otro, 'sentir con' otro. Esta reacción afectiva vicaria puede ocurrir como respuesta a unas claves perceptivas externas, indicadoras del estado afectivo de otro (por ejemplo, las expresiones faciales de una persona), o como resultado de la inferencia del estado emocional en base a claves indirectas (por ejemplo, la naturaleza de la situación del otro). Así, definimos la empatía como una respuesta emocional que brota del estado emocional de otro y que es congruente con ese estado emocional del otro (Eisenberg/ Strayer, 1992, p.15).

La empatía es nuestra capacidad de identificar lo que otra persona piensa o siente y responder ante sus pensamientos y sentimientos con una emoción adecuada (BaronCohen, 2012, p. 28).

Para que la reacción sea empática se requiere esencialmente la participación de unos procesos psicológicos que hagan que los sentimientos de una persona sean más congruentes con la situación de otra que con la suya propia (Hoffman, 2002, p. 35).

Como puede observarse, todas estas definiciones implican una dimensión afectiva, además de la propiamente cognitiva: hablan de experimentar una emoción congruente en relación al estado percibido en el otro, aunque no tenga que ser la emoción exacta del otro, ni por supuesto del mismo grado de intensidad ${ }^{6}$.

Esto es algo a tener muy en cuenta, puesto que no faltan los autores -en teoría de la mente y otras disciplinas- que consideran toda 'lectura de la mente' de otros (mindreading o capacidad de atribución mental) como empática; es decir, para

otros agentes; es decir, se trata de "una forma de inferencia teórica que utiliza un conocimiento basado en generalizaciones psicológicas" (Stueber, 2006, p. 109); b) para la teoría de la simulación, en cambio, lo que hacemos es imaginar, fabular 'como si', partiendo de la similitud psicológica de los humanos. A pesar de que existe una amplísima discusión al respecto (Stueber, 2006; Churchland, 2012; Breithaupt, 2011, etc.), parece lógico pensar que más que dos teorías que se oponen, serían dos niveles de comprensión.

5 Batson (2011) diferencia ocho usos habituales del concepto: 1. Conocer el estado interno de otra persona, incluyendo sus pensamientos y sentimientos. 2. Adoptar la postura o coincidir en las respuestas neurales del que se observa: una mímica motora. 3. Sentir lo que siente otra persona. 4. Intuirse o proyectarse uno mismo en la situación de otro. 5. Imaginar lo que estará pensando y sintiendo otro. 6. Imaginar lo que pensaría y sentiría yo estando en el lugar de otra persona. 7. Sentir malestar al ver sufrir a otra persona. 8. Preocuparse por otra persona que está sufriendo.

6 Sobre esto hay disparidad de criterios. Para Amy Coplan (2011, p. 7), por ejemplo, sólo podemos llamarlo empatía cuando "los estados afectivos del observador son cualitativamente idénticos a los del observador", mientras que para la mayoría es suficiente con que esas emociones sean "congruentes" a las del sujeto observado. Ahora bien, ¿qué significa "congruente"? Hume y Smith afirmaban que por simpatía a veces experimentamos "vergüenza ajena", aunque el sujeto observado no la sienta, obviamente. Lo mismo que nos compadecemos de alguien que ha perdido la razón y sin embargo se ríe y parece contento. ¿Hablamos con propiedad si nos referimos a 'empatía' en estos casos? Hoffman $(2002$, p. 85) cree que en algunos casos sí, pues ser un observador maduro implica un distanciamiento: "no refleja sin más el valor del estímulo inmediato, también es en parte una reacción afectiva ante la propia imagen mental" de la persona observada. 
clasificarla como tal consideran suficiente que haya una conciencia cognitiva de los estados internos de otra persona, identificando sus pensamientos, percepciones, sentimientos o intenciones. Pero según esta visión, un torturador o un sádico podría ser empático, suponiéndole una habilidad para adoptar la posición de su víctima con el fin de martirizarla con más eficacia; como serían igualmente empáticos -según esa visión, insisto- los agentes de policía, los criminólogos, los abogadores defensores o los periodistas que intentaran entender y explicar a tales sádicos, adoptando su perspectiva. Si la empatía se redujera a la dimensión cognitiva, tendríamos que decir que ha habido empatía en todos esos casos, lo cual repugna al uso común y popular del término, así como a su uso científico más consolidado, ipor no hablar de lo que dirían Hume y Smith! Porque no se trata sólo de una habilidad para saber lo que está pensando y sintiendo una persona (habilidad que podría usarse tanto para manipular como para ayudar), sino de compartir en algún grado su sentimiento. Extraña, por tanto, que haya filósofos que sigan dando por buena una definición meramente cognitiva de la empatía?

\subsection{Los mecanismos de la empatía: del contagio emocional a la adopción de perspectiva}

Los autores que conceptualizan la empatía en el sentido cognitivo-afectivo citado distinguen varias formas por las que se la puede suscitar. Para simplificar, podemos reducirlas a tres ${ }^{8}$ : 1) el contagio emocional, que algunos denominan empatía básica, "empatía de bajo nivel" o "empatía-espejo", y que se produce principalmente en el cara a cara, de manera involuntaria e inconsciente, como una transferencia automática de emociones. 2) la empatía por asociación, de manera directa cuando presenciamos la situación de otra persona y algún rasgo o estímulo de la misma o de la persona afectada nos recuerdan a otra experiencia similar vivida por nosotros mismos, suscitándonos las emociones correspondientes; o de manera indirecta, por lo que nos cuentan sobre ella o leemos sobre su situación, asociándolo a nuestras propias vivencias. 3) la adopción de perspectiva imaginativa (perspective-taking o role-taking), cuando nos ponemos en el lugar del otro -presente o ausente, cercano o lejano, real o ficticio-e imaginamos lo que piensa y siente, lo que exige el nivel más alto de procesamiento cognitivo. ${ }^{9}$

\footnotetext{
Un ejemplo claro es Martha Nussbaum, aunque a pesar de ello sigue otorgándole un papel en la moralidad: "La empatía sólo por sí misma (es decir, en los casos en que no conduce a la compasión), ¿aporta algo de importancia ética? He sugerido que no: un torturador puede emplearla con fines sádicos y agresivos. Por otra parte, sí que implica un reconocimiento muy básico de otro mundo de experiencia, y en esta medida no es completamente neutral. Si nos recreamos en la figuración de la experiencia de otra persona en nuestra mente, incluso de una forma lúdica y sin sentir interés alguno por ella, reconoceremos, aunque sea de una forma muy básica, su realidad y su humanidad" (2008, p. 373). Lo más adecuado sería denominar "adopción de perspectiva cognitiva" a esta habilidad, no "empatía".

8 Sigo a uno de los más reputados psicólogos de la empatía, Martin L. Hoffman, que lleva desde la década de 1970 desarrollando de manera sistemática su teoría. Aquí reduzco a tres y reformulo los cinco modos de suscitación empática que Hoffman (2002) desglosa: los tres primeros 'primitivos', automáticos e involuntarios (mímica, condicionamiento clásico y asociación directa) y los dos últimos (asociación mediada por el lenguaje, y adopción de rol o de perspectiva) cognitivamente más complejos.

9 Esta forma de empatía como adopción de perspectiva imaginativa tendrá su importancia en la tradición hermenéutica que arranca en el siglo XIX con Schleiermacher y Dilthey. Este último distinguió las ciencias naturales de las ciencias humanas o "del espíritu". Las primeras se dedicarían a explicar (Erklären) los fenómenos en términos de causa y efecto, mientras que las segundas tendrían como fin comprender (Verstehen)
} 
Pues bien, las formas más sencillas de la empatía "se relacionan con las más complejas como una muñeca rusa", resume De Waal (2007, p. 66). Las reacciones más básicas e instintivas, demasiado rápidas como para estar sometidas a un control consciente, implican "una serie de sustratos psicológicos compartidos: ver el desagrado o el dolor del prójimo es muy parecido a sentirlo", sigue De Waal, lo que lleva a menudo a conductas de consuelo o de ayuda. Las descripciones de la psicología y la etología comparada muestran muchas conductas empáticas de ese tipo en el reino animal (un hecho sobre el que ya insistía Hume en su Tratado), lo cual no es de extrañar desde el punto de vista evolucionista, dado el valor que encierra la empatía para la supervivencia de seres tan interdependientes. Las formas más complejas de la empatía, en cambio, requieren de un desarrollo cognitivo mucho más elevado y son privativas de los humanos, si bien, siguiendo el modelo de la muñeca rusa, "las capas exteriores necesitan de las interiores".

Detengámonos en la forma cognitivamente más compleja, la que amplía de manera significativa el alcance de la empatía: la adopción de perspectiva. Es ésta la que, por ello mismo, tendría los lazos más relevantes con la moralidad según muchos autores. Pero también aquí es necesario afinar más y fijarnos en los diferentes modos que puede adoptar. Siguiendo de nuevo a Hoffman (inspirado en este punto por las investigaciones de Stotland de los años 60), distinguimos varios tipos de toma de perspectiva:

a) Adopción de perspectiva centrada en uno mismo. Es decir, imaginarme qué sería para mí estar en $t u$ situación (y sentir en concordancia). A menudo ocurre que las circunstancias en las que se encuentra una persona o su reacción ante ellas nos recuerdan sucesos parecidos de nuestra vida, o nos hacen pensar que tales cosas pudieran pasarnos también a nosotros. Ese recuerdo o esa proyección emocionada pueden acrecentar la reacción empática, pero corren al mismo tiempo el peligro de la "desviación egoísta": dejar de prestar atención al otro y centrarme en mi propia situación.

b) Adopción de perspectiva centrada en el otro. Imaginarme qué supone para ti estar en $t u$ situación (y sentir en concordancia); es decir, no con $m i$ carácter y $m i$ mentalidad, sino con los tuyos, lo que implica tener cierta información relevante de tu persona y de tus circunstancias. Requiere una gran apertura y flexibilidad mentales, un importante ejercicio de descentramiento, sobre todo cuando la otra persona es muy diferente a nosotros.

c) Adopción combinada de perspectivas. Imaginarme la situación tanto desde mi punto de vista como del tuyo, o ir y volver de mi perspectiva a la tuya, abarcando los diferentes puntos de vista.

Esta tercera opción es la menos estudiada, pero para los autores que la señalan se trataría del "tipo de posición más eficaz" (Hoffman, 2002, p. 58), el que se correspondería con una "empatía madura" (Oxley, 2011, p. 22). En cuanto a las dos formas principales, numerosos experimentos han confirmado que la primera, la posición autocentrada, provoca un afecto empático más intenso que la centrada en

\footnotetext{
la acción humana, atendiendo a la vida psíquica de los individuos, las razones y la intencionalidad, el significado que otorgan a sus acciones. Este ejercicio comprensivo se relacionó pronto con la Einfühlung, la empatía: comprendemos las acciones poniéndonos -al menos cognitivamente- en el lugar de quienes las ejecutan o las padecen, entendiendo la forma en que las dotan de sentido, individual y colectivamente; recreando, en definitiva, la experiencia interna, los valores y las intenciones que guían a los sujetos, no menos que las circunstancias del contexto.
} 
el otro. Es fácil entender por qué: porque conecta directamente el estado afectivo de la persona observada con el sistema de necesidades del propio observador. Es fácil entender también que este ejercicio tiene sus peligros. Por un lado, el efecto antes señalado de la "desviación egoísta", pero también el peligro del "malestar personal": compartir la mala situación o el sufrimiento de la otra persona es desagradable, y muchas veces puede promover una conducta de evitación más que de ayuda. Además, la adopción de perspectiva autocentrada corre el riesgo de ciertos malentendidos, como el del llamado "efecto del falso consenso", derivado de nuestra fuerte tendencia a atribuir incorrectamente al otro nuestros propios deseos o pensamientos.

Por consiguiente, no son pocos los que alaban en primer lugar la adopción de perspectiva centrada en el otro, que evita muchos de los riesgos citados. Encontramos una primera y encendida defensa de este mecanismo en el propio Adam Smith, quien lo utiliza como argumento para contestar a los que, como Mandeville, insisten en la naturaleza egoísta del ser humano:

Aunque es correcto argumentar que la simpatía surge de un imaginario cambio de papeles con la persona principalmente afectada, no se supone que este cambio imaginario tiene lugar en mi propia persona y carácter sino en los de la persona con la cual yo simpatizo. Cuando me duelo por la muerte de su único hijo, con objeto de identificarme con su aflicción, no pienso en lo que yo mismo, una persona con tales características y profesión, sufriría si tuviese un hijo y ese hijo desgraciadamente muriese; lo que hago es considerar cuánto sufriría yo si yo fuese en realidad usted, y no sólo cambio con usted el contexto sino también las personas y los caracteres. Mi pesadumbre, entonces, obedece por entero a su causa y en nada a la mía. Por consiguiente, no es egoísta en absoluto. (...) La explicación de la naturaleza humana, pues, que deduce todos los sentimientos y afectos del amor propio (...) proviene a mi juicio de una confusa y falsa interpretación del sistema de la simpatía (Smith, 2004, pp. 537-538) ${ }^{10}$.

\subsection{La hipótesis Empatía-Altruismo y otras implicaciones}

En definitiva, comenzamos a vislumbrar que la empatía es un fenómeno impresionantemente complejo. Para empezar, porque el concepto hace referencia a un mecanismo intersubjetivo de amplísimo espectro y múltiples ramificaciones.

10 Schopenhauer (1840) sostiene una interpretación muy parecida. Al contestar a Kant y defender que el fundamento de la moral está en nuestra capacidad de compasión, critica el error de creer que "la compasión nace por un engaño instantáneo de la fantasía, al ponernos nosotros mismos en el lugar del que sufre y creer en la imaginación que sufrimos su dolor en nuestra persona. Pero no es así de ninguna manera; sino que a cada momento nos queda claro y presente que él es el que sufre, y no nosotros; y es directamente en su persona, no en la nuestra, donde sentimos el sufrimiento para aflicción nuestra. Sufrimos con él, es decir, en él: sentimos su dolor como suyo y no imaginamos que sea el nuestro; incluso, cuando más feliz es nuestro estado y más contrasta así nuestra conciencia del mismo con la situación del otro, tanto más receptivos somos para la compasión" (2009, p. 255). Al igual que Rousseau, Schopenhauer se centra sólo en la compasión, pues cree que "la participación inmediata en el otro está limitada a su sufrimiento y no es excitada, al menos no directamente, por su bienestar: sino que este, en sí y por sí, nos deja indiferentes" (2009, p. 253). Ni Hume ni Smith estarían en absoluto de acuerdo con esto: la simpathy de ambos, al igual que el uso contemporáneo de empatía, es entendida como una correspondencia con las emociones del otro, incluidas por supuesto las amables y alegres. Tampoco lo estaba Scheler (1923), quien analiza la ligazón de la simpatía tanto con la compasión como con la congratulación. En su estudio fenomenológico, concibe siempre la "simpatía genuina" como la centrada en el otro, diferenciándola de la autocentrada o egoísta (2005, pp. 78-80). 
De hecho, para evitar confusiones y limitar el uso del término empatía dentro del continuum de ese espectro, algunos filósofos (como Peter Goldie, 2000, o Amy Coplan, 2011) ${ }^{11}$ proponen aplicarlo únicamente a las operaciones cognitivamente más complejas, conscientes y voluntarias, y en concreto al modo de role-taking centrado en el otro, ése que acabamos de leer ensalzado por Smith. Pero este tipo de propuestas tiene poco éxito más allá de cierta literatura académica, porque chocan con el uso popular del término y también con gran parte de su uso científico. Al fin y al cabo, ¿por qué hacer el corte en ese punto del espectro y no en otro? Porque la empatía, así delimitada, sería más susceptible de motivar conductas prosociales o morales, sin desviación egoísta, parecen querer decir. ¿Pero es eso así, y no lo es en los demás casos?

En las últimas décadas se ha realizado una gran labor desde la psicología para investigar empíricamente cuáles son los efectos de la empatía, cómo puede medirse, cómo influye en el desarrollo moral del niño y del adolescente, qué tipo de procedimiento empático es más eficaz para promover conductas de ayuda, cómo se pueden aplicar estos conocimientos a la pedagogía, cómo a la resolución de conflictos, cómo a la integración y rehabilitación de delincuentes, etc. Obsérvese que con la amplia definición propuesta, que incluye una conexión emocional con todo tipo de sentimientos ajenos, desde los más alegres a los más apesadumbrados, la empatía no necesariamente ha de producir unos efectos claros; más allá, bien entendido, de un cierto descentramiento del yo y una sensible apertura hacia las necesidades, afectos y pensamientos del otro. Por eso no es de extrañar que el efecto más estudiado y resaltado sea el que, a través de un sentimiento de compasión o solidaridad, motive una conducta de ayuda.

Así lo estudió, entre otros, uno de los psicólogos más influyentes, Daniel C. Batson (1991, p. 89): "La empatía es una emoción vicaria orientada hacia el otro, producida al adoptar la perspectiva de una persona que se percibe como necesitada de ayuda. Es diferente del malestar personal. La magnitud de la emoción empática está en función de la magnitud de la necesidad percibida y de la fuerza del apego del observador con la persona necesitada". Sobre este presupuesto, Batson formula su conocida hipótesis Empatía-Altruismo: "la emoción empática origina una motivación altruista para reducir la necesidad del otro"12. Pues bien, en los años 80 desarrolló decenas de experimentos para testar empíricamente esta hipótesis, con todo tipo de variantes: planteando a los participantes diferentes situaciones de necesidad de ayuda, indicándoles el tipo de perspectiva que debían utilizar (impersonal; centrado en uno mismo; centrado en el otro), midiendo la alta o baja facilidad de evitación, etc. Los resultados son variopintos, pero, en lo esencial, concluía que en muchos casos (y especialmente en los de adopción de perspectiva centrada en el otro) la empatía sí produce esa motivación altruista y esa conducta de ayuda. Ninguna sorpresa a ese respecto.

11 También sugieren una limitación parecida varios neurocientíficos expertos en la empatía, como Decety y Cowell (2014a y 2014b), quienes proponen abandonar el término demasiado abarcador (catch-all term) de 'empatía' a favor de otros conceptos más precisos (como ‘intercambio emocional', 'preocupación empática' y 'adopción de perspectiva afectiva'). "Ello evitaría la confusión tanto académica como popular entre 'empatía' y moralidad", concluyen.

12 Es importante subrayar que Batson centra la distinción egoísmo/altruismo en la motivación, no en los efectos. Así, "el altruismo es un estado motivacional cuyo último propósito es aumentar el bienestar de otro", mientras “el egoísmo es un estado motivacional cuyo último propósito es aumentar el propio bienestar” (1991, pp. 6-7). 
Como tampoco supone ninguna sorpresa constatar que la empatía está expuesta a todo tipo de sesgos, que no "funciona" siempre ni con cualquier individuo y que hay varios factores que pueden alterarlo. Es hora de que los repasemos.

\section{Sesgos y limitaciones de la empatía}

\subsection{Parcialidad por inmediatez, familiaridad y semejanza}

Pensemos en las limitaciones más evidentes, aquellas que insisten en la parcialidad que caracterizaría a la empatía. Para empezar, en la forma de suscitación empática más básica y habitual, aquélla que se produce en el cara a cara; el refrán ojos que no ven, corazón que no siente (o como dicen en inglés, out of sight, out of mind) no puede ser más certero en este punto. Como es bien sabido, nos conmueven sobre todo las desgracias que se despliegan ante nuestros ojos, aquellas que suponen proximidad, visibilidad, o incluso espectacularidad. Este sesgo de la inmediatez, del aquí y ahora, puede ser superado por supuesto por las formas empáticas más complejas, por nuestra capacidad de imaginar asimismo a aquellos ausentes o lejanos. Pero no deja de ser un sesgo habitual y determinante.

Estrechamente unido a él, tenemos el sesgo por familiaridad o por semejanza ${ }^{13}$. Es comprensible, desde un punto de vista evolucionista, que la selección natural haya favorecido la empatía hacia los familiares cercanos y los miembros del propio grupo, en detrimento de los lejanos o desconocidos, pues los que están presentes, cara a cara, suelen ser los primeros. De la misma manera que es comprensible que empaticemos con más facilidad con aquellos que comparten nuestra forma de vida o que consideremos similares a nosotros; para empezar, porque requiere un ejercicio imaginativo menor: cuanto más como yo figuremos al otro, más fácil nos resultará ponernos en su lugar (con mayor o menor acierto) y emocionarnos con su circunstancia. Por la misma razón, es sabido que "todas las barreras sociales -o de clase, religión, etnia, género u orientación sexual- se muestran recalcitrantes al ejercicio de la imaginación y esta contumacia obstaculiza la emoción" (Nussbaum, 2008 , p. 356). De nuevo, no queremos afirmar que no se pueda empatizar con los muy diferentes a uno mismo, sino sencillamente que requiere un ejercicio cognitivo más esforzado y una mayor apertura emocional.

\subsection{Empatía y contra-empatía}

O como se diría en términos clásicos: simpatía y antipatía. Hume ya dejó claro que, además de la simpatía ("o comunicación de sentimientos y pasiones"), otro mecanismo cotidiano que nos influye sobremanera es la comparación, es decir, que tendemos a juzgar más los objetos por comparación que por su valor o mérito intrínsecos. Pero

13 Hume sostenía que la simpatía operaba según las relaciones de semejanza, de contigüidad espacio-temporal y de causa-efecto. Así, "vemos que allí donde existe, además de la semejanza general de nuestra naturaleza, una peculiar similitud en nuestra forma de ser, carácter, país o lenguaje, todo ello facilitará la simpatía” (2005, p. 441).

En otro artículo (Altuna, 2018) analizo más detenidamente la adopción de perspectiva imaginativa, así como otras funciones de la imaginación en la tarea ética". 
como ninguna "es más obvia que la que tiene por punto de referencia a nosotros mismos", resulta que esta comparación se mezcla "con la mayoría de nuestras pasiones", operando a menudo de forma directamente contraria a la simpatía. Ése es el caso de la envidia y la malicia, que dan lugar a "una especie de piedad al revés": "la desgracia ajena nos proporciona una idea más viva de nuestra felicidad; la felicidad ajena, de nuestra desgracia". Por ello, en lugar de reacciones empáticas, la primera puede producir deleite y la segunda malestar (Hume, 2005, p. 512).

Más complicado todavía. Porque los humanos tendemos a explicar los hechos según sus causas, y según qué o quién consideremos que ha originado la situación de la persona observada, nuestra reacción puede ser empática, indiferente o contraempática. Esa interpretación de las causas lleva a que la emoción empática (aflicción empática, pongamos, ante una persona dolida o violentada) pueda dar lugar a diferentes sentimientos morales. Hoffman (2002, p. 16) diferencia los cuatro siguientes: 1) si la víctima no puede controlar la causa (enfermedad, accidente, agresión), la aflicción empática de los observadores se convierte en compasión; 2) cuando la causa es una tercera persona, la aflicción empática suele convertirse en ira empática; 3) cuando hay una discrepancia entre el carácter de la víctima y lo que le cabe en suerte (por ejemplo, cuando a una buena persona le pasa algo malo), la aflicción empática del observador puede transformarse en un sentimiento empático de injusticia; 4) si los observadores no prestan ayuda o bien fracasan en sus esfuerzos de ayuda, su aflicción empática puede derivar en un sentimiento de culpa por inacción.

Habría mucho que decir respecto a cada uno de esos sentimientos morales, pero fijémonos al menos en uno de ellos: la ira empática. Por una parte, entendida como indignación contra el causante de un daño percibido como injusto podemos considerarla, junto con la compasión por la víctima, uno de los sentimientos básicos de lo que denominamos sentido de la justicia. Pero, por otra parte, tampoco es difícil percibir ahí otra posible fuente de distorsión en contextos sociales de rivalidad u hostilidad intergrupal: la parcialidad de la empatía a favor del grupo primario propio, ligado con esa ira empática, puede hacernos creer que tenemos que atacar a otros para defender a nuestro grupo o, en cualquier caso, alimentar sentimientos contraempáticos frente a ese grupo.

Como explica con claridad Pinker, "nuestras reacciones emocionales, lejos de reproducir automáticamente las de otras personas, pueden girar $180^{\circ}$ en función de si sentimos que estamos aliados con ellas o, por el contrario, compitiendo con ellas"; de modo que "la solidaridad suele determinar el contagio, no al revés". Y sigue:

La empatía, en el sentido moralmente pertinente de preocupación solidaria, no es un reflejo automático de nuestras neuronas espejo. Se puede encender y apagar e incluso convertir en contraempatía, a saber, sentirse uno bien cuando otro se siente mal y viceversa. La venganza puede provocar contraempatía, y las respuestas cambiantes de los seguidores deportivos revelan que la competición también puede provocarla (Pinker, 2012, p. 751).

\subsection{El interruptor que se enciende y se apaga}

"Se puede encender y apagar", acabamos de leer. Y es que, como explica el psicólogo Baron-Cohen (2012, p. 27), la empatía se produce "cuando suspendemos nuestro enfoque de atención único centrado exclusivamente en nuestra mente, y, en su lugar, 
adoptamos un enfoque de atención doble que también se centra en la mente del otro". Pues bien, ese enfoque dual "se apaga y enciende", como una bombilla, aunque en realidad se parece más a "un interruptor regulador de intensidad que a un interruptor de "todo o nada"" 14 .

En los casos más extremos, ese apagón puede deberse a características psicológicas estables que hacen que el individuo habite en un profundo y arraigado egocentrismo, instalado en ese "enfoque de atención único". Baron-Cohen estudia estos casos de "empatía cero": la psicopatía, el trastorno límite de personalidad y el narcisismo, tres tipos en los que esa ausencia total de empatía puede llevar fácilmente a la crueldad. Estudia también otro tipo que, por el contrario, no suele llevar a ella: el síndrome de Asperger y otros trastornos del espectro autista ${ }^{15}$. En cualquier caso, sin llegar a esas patologías, lo más habitual, lo que nos ocurre a todos a diario, es que ese apagón o esa bajada de intensidad del enfoque dual que necesita la empatía sea transitorio y reversible, debido a una tensión emocional, porque nos sentimos estresados o fatigados, deprimidos o enfadados, o bien porque estamos plenamente imbuidos en nuestra tarea. Además, claro, de por las razones arriba señaladas: hostilidad personal o grupal, prejuicios contra un determinado colectivo, cosificación del otro... Es claro que la empatía requiere cierta receptividad y apertura emocional.

Asimismo, cuando estamos sobreexpuestos a una situación de penuria, al vivir o visitar por ejemplo un país pobre donde nos rodea una multitud de niños descalzos, normalmente se produce una habituación, es decir, una cierta insensibilización adaptativa. La sobreestimulación puede llevar así a un "cansancio de compadecer", y es que si empatizásemos y sufriéramos con todo el que esté necesitado e intentásemos ayudarle, difícilmente podríamos seguir con nuestra vida. La verdad es que esa empatía promiscua o difusa es poco probable, gracias precisamente a esos mecanismos autorreguladores ${ }^{16}$.

14 Por supuesto, lo mismo puede decirse de nuestra capacidad racional (que se enciende y se apaga, que se parece a una bombilla de intensidad variable, que algunos tienen 'apagones' estructurales y otros pasajeros, etc.) y, sin embargo, ello no suele utilizarse como argumento sobre las "limitaciones” de la razón. Excepto en la explicación psicológica de su uso habitual, claro está, que es precisamente lo que estamos explorando en este apartado.

15 Es muy llamativo el caso de las personas con síndrome de Asperger y otros tipos de autismo, pues si bien les imposibilitan para la empatía, no les hacen amorales ni inmorales: "Aunque es posible que la mayoría de las personas desarrollen sus códigos morales a través de la empatía, estos individuos lo han hecho a través de la sistematización. Tienen un fuerte deseo de vivir con reglas, y esperan que los demás hagan lo mismo por una cuestión de justicia" (Baron-Cohen, 2012, p. 121). Varios filósofos utilizan este tipo de estudios empíricos en torno al autismo para cuestionar que la empatía sea necesaria para la moralidad (por ejemplo, Maibom, 2010).

16 Los estudios del test de empatía muestran que ésta está distribuida en forma de curva de campana entre la población. Es decir, que unos pocos tienen empatía-cero (como los casos arriba referidos) y otros pocos tienen una personalidad extraordinariamente empática; la mayoría se encuentra en algún nivel intermedio. Ello se entiende "porque los niveles de empatía moderados son más adaptativos. Estar demasiado centrado en los demás significa que uno nunca luchará por sus ambiciones, ni actuará de forma competitiva por miedo a disgustar o despreciar a los demás (...). Encontrar el equilibrio para los niveles de empatía de la mayoría puede ser una adaptación evolucionada que confiere a la persona los beneficios de la empatía, sin sus desventajas" (BaronCohen, 2012, p. 173). Baron-Cohen analiza asimismo (2005) el hecho ratificado por numerosos estudios de que las mujeres son, en general, más empáticas que los hombres. Un cuestionamiento de esto último desde la filosofía feminista en Oxley, 2011. 


\section{Empatía e ideal regulativo: la combinación ética}

\subsection{Empatía: "centro del universo moral" para algunos, elemento distorsionador para otros}

Si recapitulamos las principales aportaciones teóricas sobre la empatía, observamos dos tendencias claras. Por un lado, la puramente descriptiva, la de los científicos que la analizan como una experiencia psicológica, sin obviar los sesgos y limitaciones que caracterizan su ejercicio efectivo ${ }^{17}$. Por otro lado, la de algunos autores procedentes de la filosofía, las ciencias sociales o las humanidades, que tienden a otorgarle una fuerte carga normativa, a menudo obviando dichas limitaciones ${ }^{18}$. En realidad, la mayoría de autores que ponen a la empatía como piedra angular de la moralidad hacen referencia - explicitándolo o no- a una empatía madura, regulada o ideal, y, en general, a la combinación de ese ejercicio de descentramiento del yo con principios éticos y procedimientos de imparcialidad y universalidad.

Acabo de afirmar que son 'mayoría' los que lo plantean así, es decir, no todos. Los filósofos morales interesados en la empatía actualizan y a menudo reivindican los planteamientos de Hume y Smith, y provienen en gran parte del ámbito del sentimentalismo moral y de la ética del cuidado. Aun compartiendo este origen, hay serias discrepancias entre ellos. Encontramos dos ejemplos extremos en Michael Slote y Jesse Prinz.

Slote va más allá que otros teóricos de la ética del cuidado al abogar, como resume Carol Gilligan, por "una revolución copernicana en la filosofía moral, desplazando la empatía y las relaciones de la periferia al centro del universo moral" (en Slote, 2007); de hecho, propone replantear toda la filosofía moral a través de ese prisma, es decir, aproximarse "tanto a la metaética como a la ética normativa a través de la noción o el fenómeno de la empatía" (2010, p. 4). Partiendo de las investigaciones de Batson y Hoffman, e interpretándolos a su manera, Slote hace derivar todas las obligaciones morales de la empatía: el nivel de compromiso "natural" con los otros correspondería a nuestras obligaciones para con ellos, de manera que las diferencias en la fuerza de la empatía hacia los otros corresponderían a "las diferencias en la evaluación moral intuitiva" (2007, p. 35). Según él, la empatía no necesitaría de la

17 Si dejamos a un lado los investigadores principales de la empatía y acudimos a otros conocidos psicólogos cognitivos que -aunando evidencias científicas interdisciplinares- pretenden explicar el fenómeno moral, nos encontramos con diferentes resultados. Para Hauser (2008), por ejemplo, si bien la empatía tiene un papel importante en la "mente moral", no es el primero ni el principal mecanismo, pues, a su juicio, antes de las emociones existen las intuiciones inconscientes que compondrían una suerte de "gramática moral universal": "Si esta concepción es correcta, entonces nuestras emociones, incluida la empatía de Hoffman, vienen a continuación, como mecanismos psicológicos desencadenados por un juicio moral inconsciente" (2008, p. 57; se refiere a Hoffman porque lo considera el principal continuador de Hume en la psicología contemporánea).

Para Pinker (2012), por otro lado, la empatía es uno de los "cuatro ángeles que llevamos dentro", y es equilibrada o complementada con los otros tres: sentido moral (diferente a la empatía, tal como propone Hauser), autocontrol (regulación emocional) y racionalidad (capacidad de abstracción y universalización).

18 Desde las ciencias sociales, el ejemplo más claro tal vez sea el de Jeremy Rifkin. A pesar del protagonismo que le otorga en su monumental libro La civilización empática, no llega a definir lo que es la empatía, ni da excesiva importancia a su tendencia a la parcialidad. Por el contrario, lo plantea siempre de un modo absolutamente idealizado: "La conciencia empática sí que salva esta distancia [entre es y debería ser]. La conducta empática (...) es al mismo tiempo descriptiva y preceptiva". "Ser verdaderamente humano es sentir una empatía universal y dotar de rectitud moral la propia experiencia corpórea" (Rifkin, 2010, p. 174). 
corrección de principios morales más objetivos o sistemáticos, y su tendencia a la parcialidad, o el hecho de que sea altamente variable de una persona a otra, de un tipo de cultura y de socialización a otra, no sería realmente un problema. Algo que, al igual que Oxley (2011), Kauppinen (2014), y otros, considero insostenible.

Prinz (2011a y 2011b), por el contrario, plantea una versión del sentimentalismo moral en la que la empatía no juega un rol determinante. De hecho, rebaja de manera muy crítica el papel que ésta pueda tener tanto en el desarrollo, como en la motivación y en el juicio morales, y subraya que, en realidad, "puede interferir con los fines de la moralidad", pues "una moralidad basada en la empatía llevaría a un trato preferencial y a grotescos crímenes por omisión. La empatía puede cumplir ciertas tareas positivas en la cognición moral, como promover la preocupación por los cercanos y queridos, pero no puede ser el componente motivacional central de un sistema moral" (2011a, p. 227). Es decir, también él hace referencia únicamente a esa empatía inmediata, habitualmente sesgada, y no a la regulada o ampliada ${ }^{19}$, a la que prestaremos atención a continuación.

\subsection{Casos de conflicto entre empatía (atención, cuidado) y justicia; parcialidad e imparcialidad}

La empatía "no es una autopista directa hacia la ética", indican los pensadores que utilizan argumentos parecidos a los que acabamos de leer en Prinz (por ejemplo, Goldie, 2000, o Decety/Cowell, 2014a). Al fin y al cabo, ¿cómo podría cumplir el criterio filosófico moral de la imparcialidad, si la empatía se caracteriza por los sesgos de parcialidad?

La empatía sería en todo caso selectiva, ideal para afianzar los lazos de una moral de proximidad; ideal para comprender y atender, cuidar y ayudar a aquellos con los que interactuamos a diario, a los más cercanos y queridos (y eventualmente a otros más alejados de ese círculo); ideal para hacer la convivencia más agradable, e ideal para responder con mayor sensibilidad a las necesidades o los requerimientos del prójimo.

Ahora bien, ello podría ser perfectamente compatible con todo tipo de rivalidades intergrupales, así como con estructuras sociales clasistas, sexistas o racistas, por ejemplo: todas esas jerarquías y diferenciaciones no harían sino determinar quién es el semejante, el prójimo en quien uno puede o debe reconocerse y con el que empatizar (la empatía básica, la especular y prerreflexiva, podría seguir activándose de manera automática también ante otras personas fuera de ese círculo -en las situaciones de cara a cara más dramáticas, por ejemplo-, pero con frecuencia conduciría a un malestar personal y a una rápida conducta de evitación). Así que, más allá del alcance y las limitaciones de nuestros sentidos y de nuestra imaginación, la empatía dependerá también de los principios morales por los que determinemos quiénes son nuestros semejantes, de si fomentamos únicamente solidaridades locales

\footnotetext{
19 Por supuesto, Prinz también se plantea si la empatía puede mejorarse como afirman sus promotores, y responde que para ello necesitaríamos, entre otras cosas, mejorar su naturaleza selectiva, combinándola con algún procedimiento de imparcialidad (como la aproximación kantiana, o como la del espectador ideal de Smith). Sin embargo, una vez desarrollado ese mecanismo de imparcialidad, considera que la empatía podría resultar "superflua", o incluso algo a evitar. Su recomendación es que hagamos un esfuerzo "para centrar la reflexión moral en lo que ha ocurrido, y no en a quién le ha ocurrido, porque la cuestión del quién invita al sesgo" (2011a, p. 228). Responden a estos argumentos de Prinz, entre otros: Passos-Ferreira, 2015; Masto, 2015.
} 
o comunitarias, o defendemos una noción de humanidad compartida, un principio de igualdad y dignidad intrínseca de todos los seres humanos.

Además de la familiaridad y la semejanza, recordemos que la otra gran fuente de parcialidad es la que proviene del aquí y el ahora, de la inmediatez ligada a los sentidos. Las tragedias que se despliegan ante nuestros ojos siempre nos conmoverán más que aquellas de las que sólo hemos oído hablar. La visibilidad y la espectacularidad son así determinantes para despertar sentimientos morales derivados de la empatía, como la compasión o la ira empática: más gente se movilizará, por ejemplo, a favor de la víctima singularizada y sobreexpuesta por los medios de comunicación, que por los miles o millones que padecen en silencio en la fría sombra de las cifras. La solidaridad o la filantropía a golpe de estos ejercicios empáticos puede dar lugar en algunos casos a notorias injusticias, en cuanto suponga utilizar la totalidad de los recursos para esos pocos casos sobreexpuestos, en lugar de para el conjunto de los que se encuentran en igual situación de necesidad.

Por no hablar de los casos de nepotismo, cuando los representantes públicos o los funcionarios reparten beneficios o puestos entre familiares y amigos, llevados por la simpatía y la cercanía, en lugar de distribuirlos según reglas de justicia y equidad a perfectos desconocidos. O pensemos en otros ejemplos cotidianos: en el estudiante que viene llorando al despacho del profesor lamentando su mal examen (tuvo un mal día, su madre está enferma, etcétera) y pidiendo otra oportunidad. ¿Empatizar con él hasta el punto de dárselo no sería injusto para el resto de compañeros? O pensemos en un empleador sensible que tiene que elegir entre contratar a un trabajador que sabe que lo está pasando mal y que necesita ese sueldo, o a otro que tiene mayores cualidades para el puesto. Lo más probable es que esté dividido y que ninguna de las dos opciones le satisfaga por completo.

Y es que, como resume Hoffman (2002, p. 183), "si en el encuentro moral participan varios interpelantes, y hay un conflicto entre atención y justicia, o entre varios grupos", sólo la empatía no nos dirá cuál es la forma correcta de proceder; es decir, por sí sola no puede satisfacer las exigencias de la justicia, sobre todo en los encuentros en que ésta se enfrenta a la atención (es decir, a los reclamos empáticos). Los individuos más maduros son aquellos que son sensibles tanto a la perspectiva de la atención como a la de la justicia, "capaces de sentir el conflicto entre ambas y vulnerables a la aflicción empática, el sentimiento de culpa por anticipación y el sentimiento empático de injusticia, según qué principio cumplan y cuál no" (Hoffman, 2002, p. 223).

\subsection{En busca de una empatía regulada por un ideal normativo}

Que el juicio empático necesita ser ampliado o regulado por normas de imparcialidad es algo que ya vieron con claridad los primeros teóricos de la simpatía. Reconociendo la tendencia al sesgo empático, Hume ofreció un mecanismo correctivo para el juicio moral: "el punto de vista estable y general". Al fin y al cabo la empatía es muy variable, y es claro que nuestras evaluaciones morales no pueden depender únicamente de esas fluctuaciones:

Las personas que nos son cercanas nos resultan más simpáticas que las lejanas; nuestros conocidos nos son más simpáticos que los extraños; nuestros compatriotas, más que los extranjeros. Y, sin embargo, a pesar de esta variación en nuestra simpatía damos una 
misma aprobación a las mismas cualidades morales en China y en Inglaterra. Estas cualidades son manifiestamente igual de virtuosas y exigen el mismo aprecio por parte de un observador prudente (Hume, 2005, p. 771).

¿Cómo puede ser? Así lo explica Hume a continuación: "Para que no se produzcan esas continuas contradicciones y podamos establecer un juicio más constante sobre cualquier asunto, convenimos en mirarlo desde algún punto de vista estable y general, de modo que en nuestros razonamientos nos situamos siempre en él, con independencia de nuestra real situación en ese momento".

Adam Smith elabora una corrección semejante con su conocida teoría del “espectador imparcial”, y de manera más sistemática que Hume. ¿Cómo se moderan nuestras pasiones egoístas o los impulsos de una benevolencia que beneficia, ante todo, a los "nuestros"? Así lo explica Smith: "Antes de poder formular una comparación apropiada entre estos intereses opuestos debemos cambiar de lugar. Debemos enfocarlos no desde nuestra posición ni desde la de la otra persona, no con nuestros ojos ni con los suyos, sino desde la posición y con los ojos de un tercero, que no mantenga ninguna conexión particular con ninguno de nosotros y que nos juzgue con imparcialidad" (2004, p. 251). Un tercero abstracto e imparcial que habita (o ha de habitar) en nosotros: "Es la razón, el principio, la conciencia, el habitante del pecho, el hombre interior, el ilustre juez y árbitro de nuestra conducta" (2004, p. 253).

Se trata, en definitiva, de juzgar desde una perspectiva en la que nuestros actos serían razonables, es decir, justificables y compartibles por las demás personas en una situación similar. Y como señalaba Hume, todo el lenguaje moral que utilizamos apunta en esa dirección: manifiesta una expectación de que los otros compartan nuestra condena o nuestra alabanza, una pretensión de que ésta se basa únicamente en las cualidades del acto o persona juzgada, no en nuestra idiosincrasia o en nuestras preferencias personales. La diferencia con las tradiciones racionalistas es que, para los sentimentalistas ilustrados, la simpatía viene antes; es la que, al poner en juego nuestros sentimientos compartidos, motiva de verdad, y no la fría razón. Ahora bien, la empatía inmediata (con sus sesgos habituales: near-dear-similar) ha de ser regulada, como hemos visto, mediante una perspectiva ideal, estable e imparcial (racional, si se quiere) ${ }^{20}$.

\subsection{Empatía y moralidad, en resumen}

Creo que, en lo fundamental, Hume y Smith iban bien encaminados: tanto en su percepción de la simpatía/empatía como mecanismo básico de sociabilidad e intersubjetividad y fuente de sentimientos morales, como en su reconocimiento de que tenía que ser equilibrada y regulada por medio de procedimientos de imparcialidad y razonabilidad. Y sustentada asimismo, añadiríamos ahora, con principios éticos sobre la libertad, igualdad y dignidad de todas las personas, principios de justicia y equidad. Pensar que éstas últimas, la pretensión de razonabilidad e imparcialidad, pueden ser soslayadas y fomentar una moral basada únicamente en el sentimentalismo y la

20 Kauppinen (2014) insiste en la importancia de esta regulación emocional, y llega a formular "una explicación sentimentalista neoclásica", cuya tesis reza así: "La mejor explicación de la variación en los juicios morales centrales es la variación en la empatía y en el ejercicio de la regulación emocional, según una perspectiva ideal”. 
empatía (por muy ampliada que sea) es un absurdo. Como también lo es la propuesta contraria: pensar, en definitiva, que los principios éticos y la pura racionalidad bastan. Como si siempre debiéramos ser -o intentar ser- exquisitamente imparciales; eso sería borrar de un plumazo la buena parcialidad: la de la amistad y el amor, la del apego y el cuidado; la de la pequeña bondad, incluso.

A lo largo de estas páginas hemos señalado algunos aspectos de la compleja conexión que existe entre la empatía y la moralidad. Es hora de que recapitulemos, resumiendo las que son, a mi juicio, las principales dimensiones de esa relación:

1. La empatía no es la fuente de los principios éticos, pero... De la mera empatía natural no se derivan los principios éticos relacionados con la imparcialidad o la equidad, pero su influencia puede ser fundamental para entender por qué nos resultan deseables esos principios. Como sentenciaba Hume: "Se aprueba la existencia de la justicia por la sola razón de su tendencia al bien común, pero hasta el bien común nos sería indiferente si la simpatía no nos hiciera interesarnos por él" (2005, p. 818).

2. La empatía y la motivación para la acción prosocial. Si las emociones, deseos y necesidades son nuestra principal fuerza motivadora, no cabe duda de que la empatía, la capacidad de sentir en/con/por el otro, puede originar e impulsar muchas tipos de conducta, de apoyo o de ayuda, según nuestra percepción de las necesidades del otro.

3. La empatía y el desarrollo moral. Es obvio que el desarrollo moral -del niño al adulto- no consiste únicamente en la progresión del razonamiento sobre cuestiones de justicia, a pesar de las brillantes teorías de Piaget y Kohlberg. Que además de las capacidades cognitivas y razonadoras, implica un desarrollo de la sensibilidad moral, de la capacidad y el hábito de empatizar, como ha estudiado Hoffman: "Alos principios morales abstractos, aprendidos en contextos didácticos en frío (clases, pláticas...), les falta fuerza motivadora. La contribución de la empatía a dichos principios es lo que los convierte en cogniciones prosociales cálidas (representaciones cognitivas llenas de afecto empático que les dan por tanto fuerza afectiva)" (2002, p. 201). Esa cognición en caliente implica, entre otras cosas, que cuando "posteriormente se activa un principio moral en un encuentro de esta índole, o incluso en contextos didácticos o de investigación, se suscita el afecto empático" (2002, p. 23).

4. La empatía y el juicio moral. Hemos afirmado que los juicios morales basados únicamente en la empatía con el agente o el paciente de una acción (igual que los basados en la contra-empatía) deberían ser sopesados o regulados por procedimientos de imparcialidad. El buen juicio debería ir precedido de un buen razonamiento moral que, a su vez, se basa en una buena deliberación. Ello implica que se buscarán las mejores razones teniendo en cuenta los intereses y los puntos de vista de todos los implicados - de manera directa o indirecta- en un problema dado. Para esa buena deliberación será fundamental, por consiguiente, la capacidad de ponerse en el lugar y en la piel de las diferentes personas afectadas; de adoptar-cognitivamente, aunque también a menudo afectiva o empáticamente- su perspectiva.

En definitiva, la empatía está lejos de proporcionar por sí sola una guía ética completa y fiable, pero sí parece estar en el centro mismo de nuestras principales prácticas morales. Como resume, una vez más, Martin Hoffman: "La mayoría de los dilemas morales de la vida suscitan empatía porque implican víctimas, se vean o no, sean presentes o futuras. A su vez, la empatía activa principios morales y, ya sea directamente o a través de ellos, influye en el juicio y el razonamiento morales" (2002, p. 207). 


\section{Referencias bibliográficas}

Altuna, B. (2018): “La imaginación moral, o la ética como actividad imaginativa”, Daimon, Revista Internacional de Filosofía 74, pp. 155-169.

Baron-Cohen, S. (2005): La gran diferencia. Cómo son realmente los cerebros de hombres y mujeres, Barcelona, Amat.

Baron-Cohen, S. (2012): Empatía cero. Nueva teoría de la crueldad, Madrid, Alianza.

Batson, D. (1991): The Altruism Question. Towards a social-psychological answer, New Jersey.

Batson, D. (2011): "These things called Empathy: eight related but distinct Phenomena", en: Decety e Ickes, The Social Neuroscience of Empathy, Massachusests Institute of Technology, pp. 3-15.

Breithaupt, F. (2011): Culturas de la empatía, Buenos Aires, Katz.

Churchland, P. S. (2012): El cerebro moral, Barcelona, Paidós.

Coplan, A. (2011): "Will the real empathy please stand up? A Case for a narrow conceptualization", Southern Journal of Philosophy 49, pp. 40-65.

Coplan, A. / Goldie, P. (eds.) (2011): Empathy: Philosophical and Psychological Perspectives, Oxford University Press.

Decety, J. / Cowell, J. M. (2014a): "The complex relation between morality and empathy", Trends in Cognitive Sciences, vol. 18 (7), pp. 337-339.

Decety, J. / Cowell, J. M. (2014b): "Friends or Foes: is empathy necessary for moral behaviour?", Perspectives on Psychological Science, vol. 9 (5), pp. 525-537.

De Waal, F. (2007): Primates y filósofos. La evolución de la moral del simio al hombre, Barcelona, Paidós.

De Waal, F. (2011): La edad de la empatía. ¿Somos altruistas por naturaleza?, Barcelona, Tusquets.

Eisenberg, N. / Strayer, J. (dirs.) (1992): La empatía y su desarrollo, Bilbao, Desclée de Brower.

Goldie, P. (2000): The Emotions: A Philosophical Exploration, Oxford University Press.

Hauser, M. (2008): La mente moral, Barcelona, Paidós.

Hume, D. (1991): Investigación sobre los principios de la moral, Madrid, Austral, EspasaCalpe.

Hume, D. (2005): Tratado de la naturaleza humana, Madrid, Tecnos.

Hoffman, M. L. (2002): Desarrollo moral y empatía, Barcelona, Idea Books.

Kauppinen, A. (2014), "Empathy, emotion regulation, and moral judgment”, en Maibom, H. (ed.), Empathy and Morality, Oxford University Press.

Maibom, H. L. (2009): "Feeling for Others: empathy, simpathy, and morality", Inquiry, 52 (5), pp. 483-499.

Maibom, H. L. (ed.) (2014): Empathy and Morality, Oxford University Press.

Masto, M. (2015): "Empathy and Its Role in Morality", Southern Journal of Philosophy 53 (1), pp.74-96

Nussbaum, M. (2008): Paisajes del pensamiento. La inteligencia de las emociones, Barcelona, Paidós.

Oxley, J. (2011): The moral dimensions of Empathy, Paldgrave MacMillan.

Passos-Ferreira, C. (2015): "In Defense of Empathy: a response to Prinz", Abstracta, vol. 8 (2), pp. 31-51.

Pinker, S. (2012): Los ángeles que llevamos dentro. El declive de la violencia y sus implicaciones, Barcelona, Paidós. 
Prinz, J. (2011a): “Is empathy necessary for morality?”, en Coplan, A./ Goldie, P.(eds.), Empathy: Philosophical and Psychological Perspectives, Oxford University Press.

Prinz, J. (2011b): “Against Empathy”, Southern Journal of Philosophy 49 (s1), pp.214-233.

Rifkin, J. (2010): La civilización empática. La carrera hacia una conciencia global en un mundo en crisis, Barcelona, Paidós.

Scheler, M. (2005): Esencia y formas de la simpatía, Salamanca, Sígueme.

Schopenhauer, A. (2009): Los problemas fundamentales de la ética, Madrid, Siglo XXI.

Slote, M. (2007): The Ethics of Care and Empathy, Routledge.

Slote, M. (2010): Moral sentimentalism, Oxford University Press.

Smith, A. (2004): La teoría de los sentimientos morales, Madrid, Alianza.

Stueber, K. R. (2006): Rediscovering Empathy: Agency, Folk Psychology, and the Human Sciences, MIT Press.

Stueber, K.R. (2014): “Empathy”, The Standford Encyclopedia of Philosophy (Spring 2014 Edition). 